\title{
Psychological Support Application Using The Real-Time Webrtc: A Case Study Of Undergraduate In Malaysian And Indonesian Higher Learning Institutions
}

\section{Mohamad Asrol Arshad ${ }^{*}$, Ahmad Hudaiby Galihkusumah ${ }^{2}$, Nor Aimuni Md Rashid ${ }^{3}$, Alya Geogiana Buja ${ }^{4}$, Raja Muhammad Hanif Raja Rizal Iskandar ${ }^{5}$}

\author{
${ }^{1}$ Lecturer, Faculty of Computer and Mathematical Sciences, UiTM Cawangan Melaka, Malaysia \\ ${ }^{2}$ Lecturer, Universitas Pendidikan Indonesia, Indonesia \\ ${ }^{3}$ Lecturer, Faculty of Computer and Mathematical Sciences, UiTM Cawangan Melaka, Malaysia \\ ${ }^{4}$ Senior Lecturer, Faculty of Computer and Mathematical Sciences, UiTM Cawangan Melaka, Malaysia \\ ${ }^{5}$ Student, Faculty of Computer and Mathematical Sciences, UiTM Cawangan Melaka, Malaysia
}

Article History: Received: 11 January 2021; Accepted: 27 February 2021; Published online: 5 April 2021

\begin{abstract}
This paper presents the investigation of a psychological support application using the Web Real-Time Telecommunication, or WebRTC, in helping undergraduates who experienced mental health due to the Coronavirus Disease 2019 (COVID-19) outbreak. In this study, the psychological support application using WebRTC was developed to assist undergraduates in dealing with mental and psychological health problems encountered during the COVID-19 pandemic. The case study was conducted by distributing a survey consisting of the sharing, consulting and profiling modules of the application that have to be answered by the respondents. This application implements WebRTC as a platform for the user of the application to 'randomly' call another user. A user can choose whether to be the caller, the receiver, or both. The caller would be able to call the receiver when the specifications are chosen while the receiver is only able to receive a call. If both are chosen, the user would be able to initiate and receive a call. In order to connect one user to another in peer-to-peer communication, a signalling server is used. The results obtained in this case study showed that the COVID-19 outbreak has affected undergraduates' mental health and the developed application is able to help the undergraduates in healing their mental health. The developed application can improve the uses of other sharing platforms such as Face Time and WhatsApp Call.
\end{abstract}

Keywords: COVID-19, Higher Education, Real-time Communication, WebRTC

\section{Introduction}

The COVID-19 pandemic has sparked new norms in learning environments in institutions of higher learning worldwide whereby undergraduates have to complete their academic semester from home. Learning has been implemented using online learning applications such as Zoom, Google Classroom, Google Meet, Cisco Webex and others [1]. The implementation of these online classes is not all held as scheduled but some are conducted based on the availability of the lecturers. This has eventually led to problems especially among undergraduates who have to face situations including family members not understanding the needs and nature of the online learning at home as well as having to carry out house chores during lecture and assignment completion periods. These situations have somehow affected their focus on their studies and indirectly affected their psychological health.

In relation to this, many alternatives have been taken by various parties to help those who suffer from mental and psychological health problems during the COVID-19 pandemic, particularly during the Movement Control Order (MCO) [2,3]. This is due to the fact that this is the first experience where a control order is closely administered to prevent the transmission of COVID-19. For example, the Malaysian government also provides a line of concerns that can be contacted to enable the citizens to share their feelings and problems faced throughout the COVID-19 pandemic. In addition, the government of Malaysia has also set up a Telegram channel to disseminate accurate information from the Crisis Preparedness and Response Centre (CPRC) to reduce doubts and worries among the citizens regarding inaccurate information spread on social media by irresponsible people which eventually can worsen the situation for those who already have mental and psychological health problems [3].

One of the alternatives is through the use of the real-time telecommunication (henceforth, RTC) platforms. This mode allows all users to exchange data with negligible latency or momentary. RTC generally refers to peerto-peer communication, not broadcast or multicast [4]. Some examples of RTC communication are Voice over IP (VoIP), Internet Relay Chat (IRC), Instant Messaging (IM), Mobile and mobile phones. Examples of applications that use RTC are WhatsApp, Skype, Telegram, Viber and others. An application developed using the WebRTC [5] open source project that was first introduced by Google in 2011 [6]. WebRTC allows real-time 
communication via the JavaScript API where users can scan the web to experience peer-to-peer synchronization via WebRTC. WebRTC provides browsers and mobile applications with audio/video calls, chats and peer-topeer file sharing without the need for third-party software or plugins [6].

Our previous research [6] only proposed the use of WebRTC to enable the peer connection with the implementation of Voice over IP (VoIP). The research only focused on the architecture and random process algorithm for call process without studying and investigating the effects of the COVID-19 pandemic on undergraduates' psychological health due to the new norm that they have to face in their learning process.

This paper presents a case study that was conducted on undergraduates using WebRTC for psychological support during the COVID-19 pandemic. This case study was conducted to investigate either the proposed psychological support provided in the application developed, WebRTC, is able to solve undergraduates' problems in providing a platform for sharing and consulting their mental issues. Section 2 provides related literatures on the issues of mental and psychological support due to the pandemic; while Section 3 presents the methodology of the case study. The results obtained from the case study are discussed in Section 4. Section 5 concludes the case study.

\section{Review of Literature}

This section reviews related literatures on psychological support application using WebRTC on undergraduates.

\subsection{Effects of COVID-19 on Higher Education sector}

The main impact of COVID-19 on the education sector is changing their daily routine, especially in terms of face-to-face learning to online learning. However, our education system is lagging in terms of digital preparedness [7]. Because of that, all universities need to take immediate steps to ensure that online teaching and learning successful. According to [8], all the universities need to prepare their students with ICT integration in their curriculum.

Another effect of COVID-19 on the education sector is financial budget. Most higher learning institutions are dependent on student fees in order to continue their operations. Thus, the COVID-19 pandemic has given a big impact on financial budgets of higher learning institutions. They also need additional funding in order to implement new environments in fulfilling the requirements in terms of health, safety as well as to facilitate remedial teaching to minimize learning losses [9]. This is because there are students who cannot continue their studies due to financial constraints brought by the spread of the COVID-19 pandemic. Hence, higher learning institutions should prevent from seeking for additional fees or contributions from parents [9].

\subsection{Mental health and psychological effects on undergraduates during COVID-19}

Tertiary students are one of the most affected groups during COVID-19 in terms of mental and psychological health. This is because they are experiencing a drastic cultural shock. They are forced to change their daily routine, especially in terms of face-to-face learning to online learning whereby it is the only available means for them to access education websites from everywhere at any time [1]. However, online learning can cause students to experience mental and psychological health problems due to constraints such as poor internet connection during online learning, shyness to interact in online learning, lack of focus, as well as lack of understanding among family members on the current learning and teaching situations. According to [10], 20.4\%,6.6\% and 2.8\% out of the 983 undergraduates experienced minimal to moderate, marked to severe and most extreme anxiety levels, respectively. This data was collected from undergraduates in Malaysian and Indonesian during the COVID-19 pandemic between April and May 2020.

In addition, undergraduates who do not comprehend lecturers' lessons delivered via online classes would also experience a sense of shyness to ask for fear of being looked down upon by their fellow classmates. In addition, they also have difficulties in asking for explanation from their classmates due to the physical distancing order. Thus, this kind of situation gives them pressure on mental and psychological health of undergraduates. According [11], students were found to poorly prepare for several e-leaning competencies.

\subsection{Mental Health Support using the WebRTC application}

The people with the serious mental illnesses have difficulties in finding the solution to their situations. However, according to [12], by integrating smart technologies, real-time applications can be as effective as faceto-face services. It can also help reduce costs and improve the quality of care. According to our previous paper [6], by using a WebRTC compatible browser, a user can, in one hand, communicate in real-time and in the other hand, stay anonymous. Thus, the WebRTC application can be one of the effective methods in reducing mental 
health and psychological problems among undergraduates. Undergraduates that have mental disorders or depression are commonly unable to share their feelings and concerns due to shyness or fear of other people's reactions. According to [13], social support can provide problem solving strategies to the individual, reduce the importance of the problem, and alleviate the harmful effects of stress experience. The implementation of psychological support platform as the model we had proposed in our previous paper [6] is used to fit this issue requirement. This application allows the caller and the receiver to communicate via Voice over IP (VoIP) anonymously.

\section{Methodology}

The objective of this study is to provide a psychological support platform during the COVID-19 pandemic for tertiary students. The methodology of this study is divided into three phases of data collection, data analysis, design and evaluation. Detailed descriptions are discussed as the following;

\subsection{Phase 1: Data collection}

The focus of this study was on undergraduates at the higher education institutions. As discussed earlier, the COVID-19 pandemic has given huge impacts on the undergraduates' mental health conditions. Therefore, we had conducted an online survey involving 100 respondents among undergraduates from higher learning institutions in Malaysian and Indonesian. The questionnaire consisted of 24 questions and was separated into three parts, which are demographic information, mental health evaluation and application evaluation.

\subsection{Phase 2: Data analysis}

A descriptive statistic was used to represent the data. The open-ended responses were analyzed to determine similar answers and repetitive similar responses which were later identified and grouped into the same response. All responses were analyzed, tabulated and represented in the form of percentages. Table 1 shows the demographic characteristics of the respondents. Based on Table 1, 51.8\% of the respondents were females and $48.2 \%$ were males. Out of the total number of respondents, $90.6 \%$ of them were undergraduates from public higher learning institutions while the rest were from private higher learning institutions in Malaysian and Indonesian. The results of the undergraduates' mental health and application evaluation are discussed in the next section.

Table 1 Demographic Characteristics of the Respondents

\begin{tabular}{|c|c|c|c|c|}
\hline $\begin{array}{l}\text { Demographic } \\
\text { Characteristics }\end{array}$ & Full name & $\begin{array}{l}\text { Number } \\
\text { Respondents }\end{array}$ & of & $\begin{array}{l}\text { Percentage } \\
(\%)\end{array}$ \\
\hline \multirow{3}{*}{ Age } & $15-20$ years old & 56 & & 69.4 \\
\hline & $21-30$ years old & 25 & & 29.4 \\
\hline & $31-40$ years old & 1 & & 1.2 \\
\hline \multirow[t]{2}{*}{ Gender } & Male & 41 & & 48.2 \\
\hline & Female & 44 & & 51.8 \\
\hline \multirow[t]{2}{*}{ Institution } & Public Higher Education Institutions & 77 & & 90.6 \\
\hline & $\begin{array}{l}\text { Private Higher Education } \\
\text { Institutions }\end{array}$ & 8 & & 9.4 \\
\hline
\end{tabular}

\subsection{Phase 3: Implementation and Evaluation}

Based on the survey, we implemented the psychological support platform as the model which we had proposed in our previous paper [6] to fit with the respondents' requirements. The psychological support platform that we had proposed is using WebRTC to enable the real-time communication and random algorithm. This application allows the caller and the receiver to communicate via Voice over IP (VoIP) anonymously. Figure 1 shows the proposed application model that was adapted for a psychological support scenario. The clients will be connected via the signalling server first. STUN/TURN Server will only be used when it involves two different network addresses, then the application server's data will be sent to the clients, therefore, the peer connection will be initiated through the roles of WebRTC. After being connected to each other, both clients will be able to communicate via VoIP. A randomizer algorithm is implemented on the application server in order to randomize the call. 


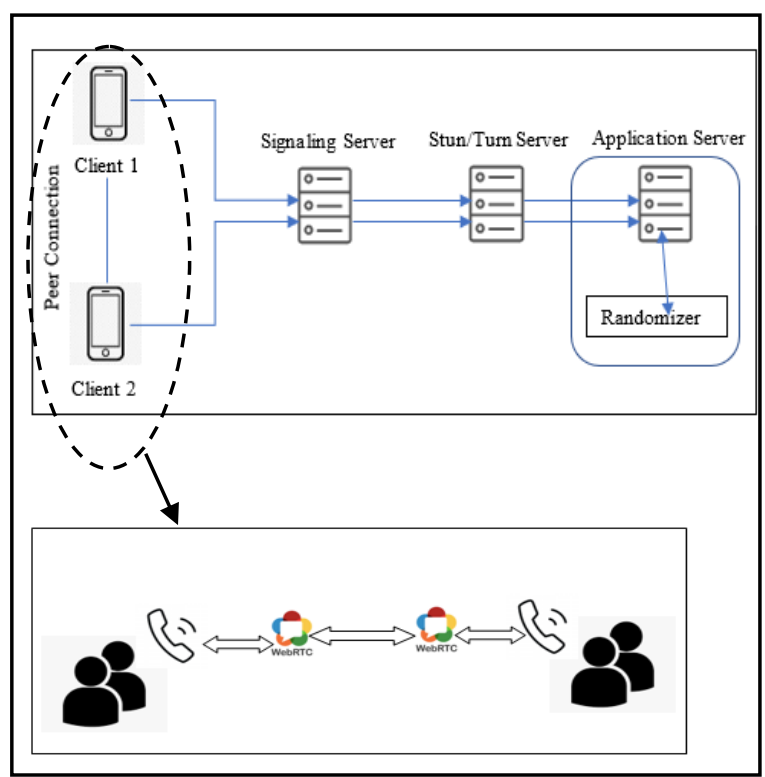

Figure 1 The proposed application model of Real-Time Communication for Psychological Support using WebRTC and Randomizer [1]

The evaluation of the application's reliability and acceptance was done through the disseminated online survey. The respondents rated the application based on four criteria; 1. Reliability, 2. User interface, 3. User adaptability to the application's functions, 4. Application's acceptance. Further discussion on the evaluation is presented in the next section.

\section{Results}

The first research question of this study was; how to identify the effects of the COVID-19 pandemic on undergraduates' mental health conditions?, while the second research question was; how is the reliability of the proposed application in helping undergraduates in coping with the mental health issues measured?. The results of the analysis are divided into two parts; 1. Undergraduates' mental health analysis, and 2. Application's Evaluation.

\subsection{Undergraduates' Mental Health Analysis}

Table 2 shows the findings from the survey conducted. The results of the analysis are divided into three categories which are: mental conditions before the COVID-19 pandemic, the impacts of COVID-19 on respondents, the rate of mental state after COVID-19, hurting self-thought, and suicidal thought. Based on the results, $30 \%$ of the respondents (20\% females and $10 \%$ males) were diagnosed with mental health problems before the COVID-19 outbreak, in other words, COVID-19 did affect the respondents' mental state. From the result, we could conclude that $65 \%$ of the respondents' mental state (rated as 1 to 3) was in jeopardy due to the pandemic. $28 \%$ of the respondents (17\% females, $11 \%$ males) did have the thought of hurting themselves during the pandemic period. Meanwhile, $20 \%$ (14\% females, $6 \%$ males) did have a suicidal thought during the period.

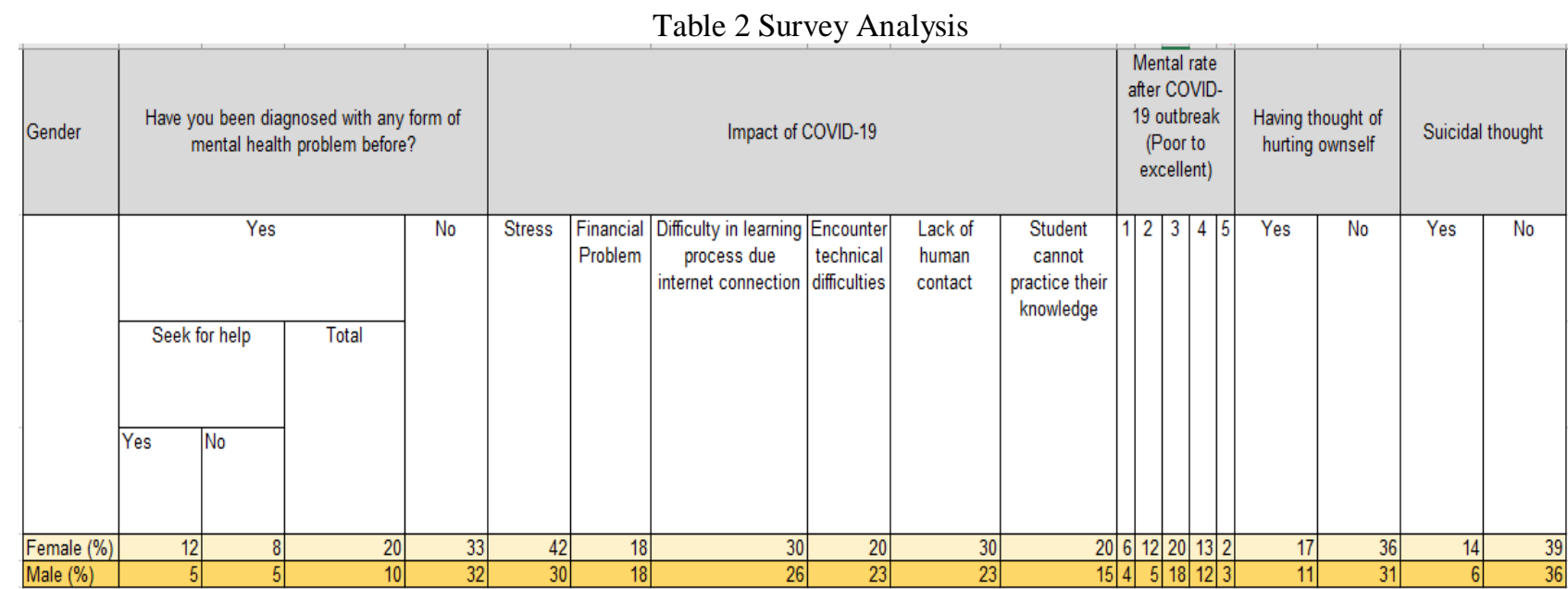


Based on the analysis, we found that some of the respondents did seek for help either from their parents, siblings or friends. However, none of the respondents sought for professional advice from the experts. $30 \%$ of the respondents that were having mental health issues did not seek for help due to few reasons. Figure 2 shows the common reasons for the respondents not to seek for mental health advice. Out of the total number of the respondents whereby $13 \%$ of them did not seek for help, $92.31 \%$ of them claimed that they were too scared to seek for any advice, while $69.23 \%$ of them also believed that no one can help them, and they did not know the appropriate step to seek for help. Meanwhile, $61.54 \%$ of the respondents hoped that the disease will be vanished naturally, and the same value showed that the respondents did not seek for any help due to public perception.

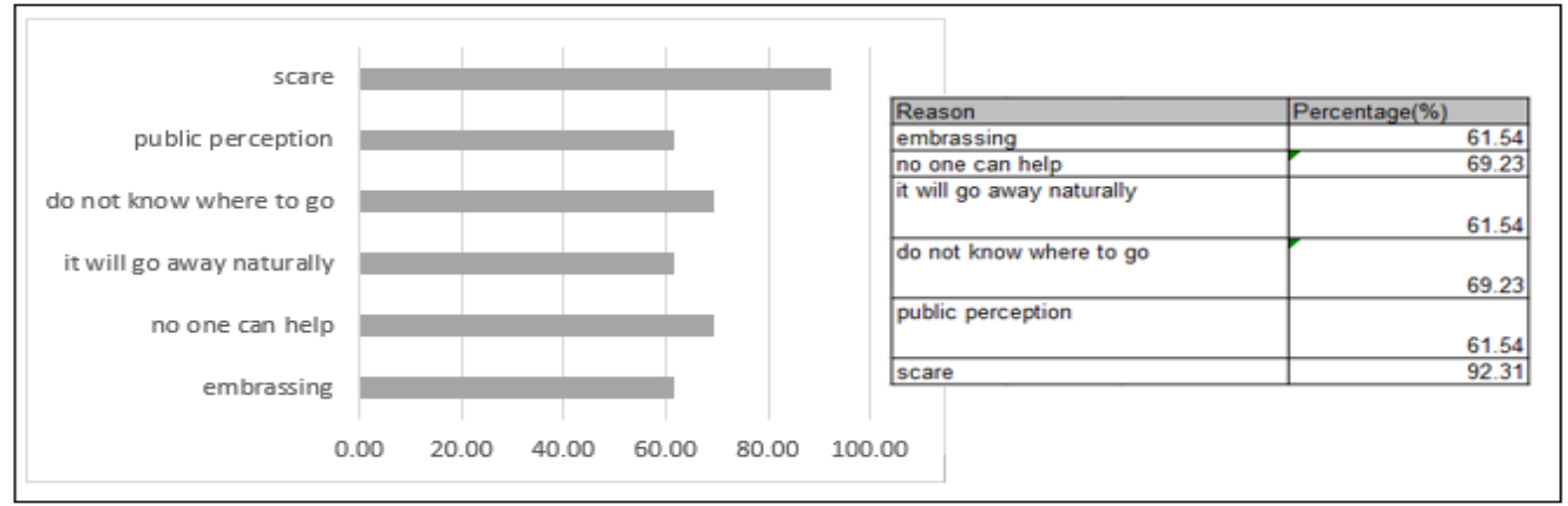

Figure 2 Analysis on Reasons of not Seeking for Help

\subsection{Application's Evaluation}

In order to help the undergraduates in coping with their mental health issues, we proposed the Real-Time application as a psychological support platform using WebRTC and Randomizer. This proposed application met our second research questions which was on how to design a platform to support psychological needs among undergraduates during the COVID-19 outbreak. The evaluation was successfully made. The application module is divided into four modules: 1. Anonymous voice call, 2. Dual interface, 3. User feedback and profiling, and 4. Overall system function.

Based on Table 3, the application modules were paired with the characteristics preferred by the respondents. We scaled the responses from the respondents using 1(poor) to 5 (excellent). The objectives of the application were achieved by considering the scales 4 and 5 . The application provides the reliability through the anonymous call and random algorithm which satisfied the respondents' needs (scale 4- 38.4\%, scale 5-33.7\%). For the user interface, which provides users with the ability to switch between as caller and receiver, it was found that $33.7 \%$ of the respondents gave the scale of 4 and $30.2 \%$ gave a scale of 5 .

Table 3 Application's Evaluation Result

\begin{tabular}{lllllll}
\hline & \multicolumn{2}{c}{ Scale (\%) } & & \\
\hline Application modules & Characteristics & $\mathbf{1}$ & $\mathbf{2}$ & $\mathbf{3}$ & $\mathbf{4}$ & $\mathbf{5}$ \\
\hline $\begin{array}{l}\text { Anonymous voice call and random } \\
\text { call }\end{array}$ & Reliability & 3.5 & 3.5 & 20.9 & 38.4 & 33.7 \\
\hline Dual interface as caller and callee & User Interface & 3.5 & 4.7 & 27.9 & 33.7 & 30.2 \\
\hline User feedback and profiling & Features Adaptability & 3.5 & 5.8 & 22.1 & 33.7 & 34.9 \\
\hline Overall system function & Application Acceptance & 2.3 & 4.7 & 26.7 & 22.1 & 44.2 \\
\hline
\end{tabular}

The application also provides users with profiling features, which users may give ratings to the caller or receiver while the application would generate the profile record of the user for future references. $33.7 \%$ of respondents rated the scale of 4 while $34.9 \%$ of them rated the scale of 5 for these features. $22.1 \%$ of respondents rated the scale of 4 and $44.2 \%$ of the respondents rated the scale of 5 for the overall system's function. Therefore, most of the users agreed that the proposed model can provide them a reliable psychological support platform during the COVID-19 pandemic.

The problems highlighted in this research are based on the needs of psychological support platform to help undergraduates who suffer from this mental illness. Based on the results, the real-time communication for psychological support was accepted by the respondents and successfully achieved the objectives of providing a platform for sharing and consulting undergraduates with mental issues. 


\section{Conclusion}

In conclusion, this paper discussed a case study that was conducted on undergraduates using the real-time WebRTC in providing psychological support during the pandemic of COVID-19. From the case study, it was found that most of the respondents did seek for help from their parents, siblings, relatives, and friends. The developed application is carefully designed with profiling features, which users may give ratings to the caller or receiver whereby the application would generate the profile record of the users for future references. The findings of the study also showed that this application is able to solve the undergraduates' problems in providing a platform for sharing and consulting undergraduates with mental issues. This application has been developed with three important modules that are not found on other platforms namely; anonymous voice and random call, dual interface and user feedback, and profiling. For future work, the developed WebRTC supporting tool for facilitating the psychological during crisis can be enhanced by developing an automated helper or adding other required modules based on other groups of users from other sectors.

\section{Acknowledgment}

The name of the persons who made some significant contribution in improvement of the authors' paper will be included in the acknowledgement section. The sources of funding can also be included in this section.

This study was conducted under the funding from Universiti Teknologi MARA Cawangan Melaka, "SKIM GERAN SEPADAN ANTARABANGSA TEJA 2020 - GSAT2020-9”.

\section{Conflicts of interest}

The authors have no conflicts of interest to declare.

\section{References}

1. Wan Hassan WAS, Ariffin A, Ahmad F, Sharberi SNM, Nor Azizi MI, Zulkiflee SN. "Covid-19 pandemic: Langkawi vocational college student challenge in using google classroom for teaching and learning (t\&l)". Int J Adv Trends Comput Sci Eng.,9(3):3299-307, (2020).

2. Harnois G, Gabriel P. Mental Health Policy and Service Development. World Heal Organ Int Labour Organ [Internet]; Available from: https://digitalcommons.ilr.cornell.edu/cgi/viewcontent.cgi?referer=https://scholar.google.de/scholar?hl= de\&as_sdt=0\%2C5\&q=Mental+health+and+work\%3A+Im-

+ pact $\% 2$ Cissues+and+good + practices $\& b t n G=\& h t t p s r e d i r=1 \&$ article $=1223 \&$ context $=$ gladnetcollect $\% 0$ Afile://C:/Us. Access date: 10.10.2020.

3. Iksal M. N. "Guidelines On Management Of Coronavirus Disease 2019 (Covid 19) In Neonates",21(1):1-9, (2020).

4. Azom EE, Dirting BD. “A Peer-To-Peer Architecture For Real-Time Communication Using Webrtc. J Multidiscip Eng Sci Stud”,3(4):1671-83, (2017).

5. Damayanti FU. "Research of Web Real-Time Communication - the Unified Communication Platform using Node.js Signaling Server”. J Appl Information, Commun Technol, 5(2):63-72, (2020).

6. Rashid NAM, Buja AG, Arshad MA, Rizal Iskandar RMHR, Galihkusumah AH. "Real-time webrtcbased application for psychological support during COVID-19". Int J Adv Trends Comput Sci Eng.,9(1.4 Special Issue):208-16, (2020)

7. Daniel SJ. "Education and the COVID-19 pandemic. Prospects" [Internet].,49(1-2):91-6. Available from: https://doi.org/10.1007/s11125-020-09464-3, (2020).

8. Ghavifekr S, Razak A, Ghani M, Ran N, Meixi Y, Tengyue Z. "ICT Integration in Education: Incorporation for Teaching \& Learning Improvement”. Malaysian Online J Educ Technol, 2(2):24-45, (2020).

9. Jiménez-Sánchez C. "Impact of the SARS-CoV2 pandemic on education". Rev Electron Educ.1-3, (2020)

10. Sundarasen S, Chinna K, Kamaludin K, Nurunnabi M, Baloch GM, Khoshaim HB, et al. "Psychological impact of covid-19 and lockdown among university students in malaysia: Implications and policy recommendations". Int J Environ Res Public Health,17(17):1-13, (2020).

11. Dhawan S. Online Learning: A Panacea in the Time of COVID-19 Crisis. J Educ Technol Syst,49(1):522,( 2020).

12. Nasreen K, Chen TB, Anusuyah S. "Adoption of Smart Real-time Mental Health System to Support Emotional Well-being among Young Adults in Post Covid Era: Role of Social Media”, 2(2):528(2020).

13. Wang X, Cai L, Qian J, Peng J. "Social support moderates stress effects on depression". Int J Ment Health Syst.,8(1):1-5, (2014). 
Mohamad Asrol Arshad, Ahmad Hudaiby Galihkusumah, Nor Aimuni Md Rashid, Alya Geogiana Buja, Raja Muhammad Hanif Raja Rizal Iskandar

14. Giacalone A, Rocco G, Ruberti E. "Physical Health and Psychosocial Considerations During the Coronavirus Disease 2019 Outbreak. Psychosomatics":1-6, (2020). 